\title{
Glucose Conjugation of anti-HIV-1 oligonucleotides containing unmethylated CpG motifs reduces their immunostimulatory activity
}

José A. Reyes-Darias $^{[\mathrm{a}, \dagger]}$, Francisco J. Sánchez-Luque ${ }^{[\mathrm{a}, \S]}$, Juan Carlos Morales ${ }^{[\mathrm{b}]}$, Sonia Pérez-Rentero ${ }^{[c]}$, Ramón Eritja ${ }^{[c]}$, Alfredo Berzal-Herranz ${ }^{*[a]}$

${ }^{[a]}$ Instituto de Parasitología y Biomedicina "López-Neyra" (IPBLN-CSIC), PTS Granada, Spain.

${ }^{[b]}$ Department of Bioorganic Chemistry, Instituto de Investigaciones Químicas, (IIQCSIC/Universidad de Sevilla, Sevilla, Spain.

${ }^{[c]}$ Institute for Advanced Chemistry of Catalonia (IQAC-CSIC), Networking Centre on Bioengineering, Biomaterials and Nanomedicine (CIBER-BBN), Jordi Girona 18-26, E08034 Barcelona, Spain.

${ }^{\dagger}$ Present address: Estación Experimental del Zaidín, (EEZ-CSIC), Granada, Spain §Present address: Genome Plasticity and Disease Group. Mater Medical Research Institute-University of Queensland, Australia

${ }^{*}$ Address correspondence to this author at the Instituto de Parasitología y Biomedicina "López-Neyra", CSIC, Parque Tecnológico de Ciencias de la Salud, Avd. del Conocimiento s/n, Armilla, 18016 Granada, Spain

Tel: +34958181648; Fax: +34958181632

E-mail: aberzalh@ipb.csic.es 


\section{Abstract}

Antisense oligodeoxynucleotides (ODNs) are short synthetic DNA polymers complementary to a target RNA sequence. They are commonly designed to halt a biological event, such as translation or splicing. ODNs are potentially useful therapeutic agents for the treatment of different human diseases. Carbohydrate-ODN conjugates have been reported to improve the cell specific delivery of ODNs through receptor mediated endocytosis. We have tested the anti-HIV activity and biochemical properties of the 5'-end glucose-conjugated GEM 91 ODN targeting the initiation codon of the gag gene of HIV-1 RNA in cell-based assays. The conjugation of a glucose residue significantly reduces the immunostimulatory effect without diminishing its potent anti-HIV-1 activity. No significant effects were either observed in the ODN stability in serum, in vitro degradation of antisense DNA-RNA hybrids by RNase $\mathrm{H}$, cell toxicity, cellular uptake and ability to interfere with the HIV-1 genome dimerisation.

Key words: Conjugated oligonucleotides, Glucose DNA oligonucleotides, HIV-1 inhibition, Immune response reduction. 


\section{Introduction}

There is considerable pharmaceutical interest in the use of synthetic antisense oligodeoxynucleotides (ODNs) to specifically interfere in the process of gene expression. ${ }^{[1]}$ Antisense ODNs are short synthetic DNA polymers (or chemical analogues) that are complementary to a target RNA molecule. They are designed to halt a biological event, such as translation or splicing. ${ }^{[2]}$ Antisense ODNs have been pursued as a major class of new pharmaceuticals for a variety of human diseases, including cancer and viral infections. ${ }^{[3]}$ After several decades of research and development, so far very few nucleic acid therapeutics have been approved for human use: Fomivirsen (Vitravene) is an antisense ODN composed of 21 phosphorothioate-linked nucleosides which was approved for the treatment of retinal inflammation caused by cytomegalovirus, but it was later withdrawn from the market. ${ }^{[4]}$ Similarly Macugen (pegaptanib sodium injection), a 28nucleotide RNA aptamer conjugated to $20 \mathrm{kDa}$ polyethylene glycol targeted to heparin binding domain of VEGF165, was approved for the treatment of wet age-related macular degeneration. ${ }^{[5]}$ Recently, the US Food and Drug Administration has approved a new lipidlowering drug: Mipomersen (marketed as Kynamro by Genzyme, Cambridge, MA, USA). This drug is an antisense molecule based on 2'-O-(2-methoxy) ethyl-modified ribose ODN developed against ApoB100 mRNA to treat the homozygous familial hypercholesterolemia. ${ }^{[6]}$ However, the clinical success achieved so far with ODNs has not been satisfactory; some of the major impediments have been recognised as their instability against nucleases, poor delivery or uptake by cell targeted, and off-target effects or toxicity among others. To address these limitations, a variety of different chemical modifications in the ODN backbone have been introduced. ODNs are quickly degraded by nucleases in both in vitro and in vivo contexts, increasing their nuclease resistance is a major issue for the development of ODN based in vivo applications. They can be degraded by both endoand exonucleases. ${ }^{[7]}$ One of the most straightforward modifications made to an ODN to 
increase the resistance to nuclease degradation, is to replace a non-bridging oxygen on the phosphate backbone with sulphur, producing a phosphorothioate (PS) linkage ${ }^{[8]}$ (Figure 1B). It has been later learned that RNA/DNA hybrids containing this modification are also substrate for RNase $\mathrm{H}^{\left[{ }^{[9]}\right.}$ which has been shown to be the molecular inhibition mechanisms of many antisense ODN by promoting the degradation of the target RNA. Methylation of the 2' position of the ribose $\left(2^{\prime}-\mathrm{OMe}\right)$ is already a standard modification to yield highly nuclease resistant ODNs. ${ }^{[10]}$ Numerous efforts have also been made to improve the pharmacokinetic and pharmacodynamic properties of antisense ODNs, and very importantly to overcome negative or undesired effects by covalently attaching, conjugating, chemical groups or molecules that may provide new properties to the ODNs. ${ }^{[11]}$ The potential application of conjugated ODNs is not only limited to therapeutics but also in diagnostics and nanotechnology. Conjugation of ODNs with cationic compounds, such as poly-(L)-lysine ${ }^{[12]}$ or polyamides, ${ }^{[13]}$ lipophilic conjugates, such as cholesterol, ${ }^{[14]}$ attachment of long chain alcohols, ${ }^{[15]}$ phospholipids, ${ }^{[16]}$ aromatic compounds, ${ }^{[17]}$ as well as polyethylene glycol ${ }^{[18]}$ have been successfully tested to pursue a more efficient ODNs delivery to specific target cells which represent an important limitation of in vivo ODN application. We have previously reported an improvement in the cell uptake of ODNs containing a terminal glucose unit linked through a long tetraethylene glycol spacer or just one doubler dendrimer in HeLa and U87-CD4 ${ }^{+}-\mathrm{CXCR} 4^{+}$human cells. ${ }^{[19]}$ Such modifications also contribute to the stability of oligoribonucleotides against 5'-end exonuclease degradation. ${ }^{[20]}$

The phosphorothioate antisense ODN GEM $91^{[21]}$, registered as trecovirsen, complementary to the initiation codon of the gag ORF of the HIV-1 RNA (positions 324$348)^{[22]}$ (Figure 1A) was shown to yield a potent anti-HIV activity in cell culture. ${ }^{[21,23]}$ Surprisingly, a transient increase in HIV-1 replication was reported in vivo when GEM 91 was administered by continuous i.v. infusion for 8 days in a blinded dose escalation 
study. ${ }^{[24]}$ To test whether this was a side-effect induced by the CpG-like motifs present in the GEM 91 ODN, a new antisense ODN (GEM 92) lacking these motifs was assayed. GEM 92 ODN resulted in a loss of this viral replication enhancement induced in vivo by the GEM 91, but exhibited an unacceptable anti HIV-1 activity. ${ }^{[25]}$ This result is in good agreement with those previous observations that ODNs containing CpG motifs mimic properties of bacterial CpG DNA activating immune response through TLR9 (Toll-like receptor 9$)^{[26]}$ and that the TLR9 ligand (CpG DNA in that study) promotes the HIV replication in ex vivo HIV-1 transgenic mouse spleen cells. ${ }^{[27]}$ Therefore, it is possible that an increase in HIV-1 copy number following administration of GEM 91 was due to activation of TLR9.

In the current work we have analysed the biological properties and anti-HIV-1 activity of the conjugation of a glucose residue at the 5'-end of the GEM 91 (Gluc-GEM 91) resulting in a significant reduction of the immune response activation while maintaining its antiviral activity and biochemical properties.

\section{Results}

\section{Stability of 5' glucose conjugated ODNs in serum}

To analyse whether ODNs modified at the 5'-end by glucose are protected from nuclease digestion the stability of phosphorothioate (PS) and phosphodiester (PO) ODNs 5' glucose conjugated (Gluc-ODN) in cell culture media containing 10\% heat inactivated FBS were compared with its parental nonconjugated ODNs. Results shown in figure 2 indicate that while the PS ODN derivatives, GEM 91 (PS) and Gluc-GEM 91 (PS), remained intact after $144 \mathrm{~h}$, the GEM 91 (PO) and Gluc-GEM 91 (PO) exhibited a half life of around $120 \mathrm{~min}$ and were completely degraded within $240 \mathrm{~min}$ of incubation. As expected the phosphorothioate substitution yielded highly resistant serum nucleases ODNs. However, 
conjugating of a glucose molecule to the 5'-end of the ODNs did not diminish their serum stability.

\section{RNase $H$ digestion of 5' glucose conjugated ODN/RNA hybrids}

RNase $\mathrm{H}$ mediated degradation of ODN/RNA hybrids has been shown to be a key event in the inhibitory molecular mechanism of many antisense ODNs. However, residue modifications could affect the ability of an ODN to trigger RNase $\mathrm{H}$ mediated degradation of RNA following hybrid formation. To analyse the effect of the 5' glucose conjugation of ODNs (Gluc-ODN) in RNase $\mathrm{H}$ digestion, an internally ${ }^{32} \mathrm{P}$-labelled HIV-1 RNA fragment containing the first 357 nt of the HIV-1 genomic RNA was synthesized in vitro and subjected to RNase $\mathrm{H}$ digestion in the absence or presence of different concentrations of unlabelled antisense ODNs (Figure 3). The predicted RNase H cleavage product (325 nt) was detected in the presence of the ODN GEM 91 (PO) or Gluc-GEM 91 (PO) at concentrations as low as $0.01 \mu \mathrm{M}$, and leading intact HIV-1 5'-UTR RNA to undetectable levels after incubation of $30 \mathrm{~min}$ in the presence of $0.1 \mu \mathrm{M}$ of either ODN. Similarly, RNase $\mathrm{H}$ digestion of the HIV-1 RNA was completed in the presence of $1 \mu \mathrm{M}$ GEM 91 (PS) or Gluc-GEM 91 (PS). No difference in the RNase $\mathrm{H}$ digestion efficiency was observed between GEM 91 (PO) and Gluc-GEM 91 (PO) or GEM 91 (PS) and Gluc-GEM 91 (PS) ODNs. This implies that the presence of the glucose molecule in the 5'-end does not interfere either with the ODN-RNA hybridisation process or with the RNase $\mathrm{H}$ digestion.

\section{Interference of the HIV-1 RNA dimerisation by glucose conjugated ODNs}

Previous results had shown that the target region of GEM 91 is involved in HIV-1 genomic RNA dimerisation. ${ }^{[28]}$ Therefore, Gluc-ODNs were tested for their ability to interfere with

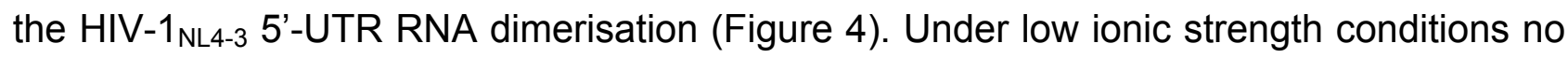
dimers were detected (Figure 4; Monomer control). In contrast, under high ionic strength 
conditions $\sim 88 \%$ of the $1-357$ HIV-1 $1_{\text {NL4-3 }}$ 5'-UTR genomic RNA fragment folded into a dimer conformation (Figure 4; Dimer control). The presence of the GEM 91 (PO) and GlucGEM 91 (PO) resulted in the reduction of dimer formation (49\% and 53\% dimer, respectively; Figure 4; lanes 5 and 6). However, poor inhibition was observed with GEM 91 (PS) and Gluc-GEM 91 (PS) (70\% and 73\% dimer yield, respectively; Figure 4; lanes 7 and 8). As expected, no inhibition of dimerisation was observed in the presence of the control ODNs pLCX-25 and Random-25 (Figure 4; lanes 3 and 4). The relative dimerisation rates of all tested ODNs, conjugated and noconjugated, were significantly different from the control, as determined by one-way ANOVA analysis ( $p<0.001)$. No significant difference in the dimerisation efficiency was observed between GEM 91 (PO) and Gluc-GEM 91 (PO). Similar effects were seen between GEM 91 (PS) and Gluc-GEM 91 (PS) ODNs. It is clear that the phosphorothioate modification slightly decreases the relative binding affinity compared with natural phosphodiester ODNs (Figure 4; compare lanes 5 and 6 to lanes 7 and 8), in agreement with the lower melting temperature of the ODN (PS)-RNA duplex relative to the ODN (PO)-RNA duplex. ${ }^{[29]}$ In addition these results also indicated that the presence of a glucose molecule covalently linked to the 5'-end of the GEM 91 ODN (PO or PS) did not modify its ability to interfere with the HIV-1 genomic dimerisation process.

\section{Anti-HIV-1 activity of 5' glucose conjugated ODNs}

The effect of the 5' glucose conjugation in the antiviral activity of the GEM 91 (PS) was tested using two different experimental strategies. Firstly, human glioblastoma U87-CD4 ${ }^{+}-$ $\mathrm{CXCR}^{+}$cells were cotransfected with 500 pmol $(1 \mu \mathrm{M})$ of ODN and $100 \mathrm{ng}$ of pNL4-3 plasmid, which contains a full infectious provirus, HIV-1 ${ }_{\mathrm{NL4}-3 .}{ }^{[30]}$ Viral particles production was measured at two days post-transfection as p24 antigen abundance in the cellular supernatant as described in Experimental Section. This represents an experimental model 
of a post-integrative viral inhibition assay. No viral particles were detected in the cell cultures transfected with either of the phosphorothioate modified ODN; GEM 91 (PS) or Gluc-GEM 91 (PS) (Figure 5A). These potent inhibitions are consistent with the previously reported data. ${ }^{[21,23]}$ Similarly, a highly efficient inhibition was seen in the presence of GEM 91 (PO) or Gluc-GEM 91 (PO) (86 and 84\% inhibition, respectively). Potent inhibition was also observed at an ODN concentration as low as $0.02 \mu \mathrm{M}$ (data not shown).

Secondly, ODNs were tested for their ability to inhibit HIV-1 replication in a viral preintegrative model. For this purpose HIV-1 infected U87-CD4 ${ }^{+}-\mathrm{CXCR} 4^{+}$cell cultures were treated with $1 \mu \mathrm{M}$ ODN and p24 antigen was measured as described in Experimental Section. A potent HIV-1 particles production inhibition was observed with GEM91 (PS) (90\% inhibition) and the glucose conjugated derivative Gluc-GEM 91 (PS) (91\% inhibition) (Figure 5B). However, little inhibitory effect was observed in GEM 91 (PO) and Gluc-GEM 91 (PO) (10\% and 20\% inhibition, respectively). Cell infection was also qualitatively monitored by microscopy as syncytium formation (Figure 6). HIV-1 infected glioma cells fuse to form multinuclear cell aggregates (syncytia), followed by cell death and eradication of monolayer cultures. In contrast to infected cell culture treated with GEM 91 (PO), GlucGEM 91 (PO) or control ODNs, no syncytia was observed in those treated with GEM 91 (PS) or Gluc-GEM 91 (PS) (Figure 6) confirming the results obtained measuring p24 antigen (Figure 5B). We further examined the effects of different ODNs on the cell viability in order to determine their toxicity. Cell viability was determined by trypan blue exclusion assay after 1-5 days post-transfection. No significant reduction of cell viability was observed at ODN concentrations up to $1 \mu \mathrm{M}$ (data not shown).

\section{Long-term protection against HIV-1 infection in Jurkat cells by Gluc-GEM 91 (PS)}

To compare the long-term efficacy of GEM 91 (PS) with that of Gluc-GEM 91 (PS), infected Jurkat cells were maintained at concentration of 1, 2, 4 or $8 \mu \mathrm{M}$ of GEM 91 (PS) or 
Gluc-GEM 91 (PS) respectively. The level of HIV-1 ${ }_{\text {NL4-3 }}$ replication was monitored throughout the time by assaying p24 levels (Figure 7). Maximum inhibition was observed after day six of ODN treatment for all the concentrations assayed, yielding inhibitions near $95 \%$ for the highest ODN concentrations tested. At day 10, the level of p24 antigen was below (5-25\%) compared to the control HIV-1 $1_{\mathrm{NL} 4-3}$ infected Jurkat cells. This high inhibition was maintained up to day 20 (80-85\% inhibition) for cell cultures treated with the highest doses of ODNs (4 or $8 \mu \mathrm{M}$ ). No significant differences were observed between cells treated with GEM 91 (PS) and Gluc-GEM 91 (PS) ODNs.

\section{Conjugation of glucose at the 5'-end of GEM 91 does not increase cellular uptake}

In order to examine whether the glucose conjugation increased the cellular ODN uptake, we compared the cellular uptake of $3^{\prime}$ end ${ }^{32} \mathrm{P}$ labelled Gluc-GEM 91 (PS) with the unconjugated control. ODNs were added to human cells HEK 293T or U87-CD4 ${ }^{+}-\mathrm{CXCR} 4^{+}$ cells in culture and incubated for 2, 4 and $8 \mathrm{~h}$. At each time point, the cells were treated with DNase I, removed from the dishes with trypsin and washed with PBS as described in Experimental Section. The total amount of ${ }^{32} \mathrm{P}$ labelled ODN taken up by cells was quantified. No significant changes in Gluc-GEM 91 (PS) and GEM 91 (PS) uptake at 2, 4 or $8 \mathrm{~h}$ were observed (Figure 8 and data not shown). Throughout the ODN incubation there is nearly a linear increase of total cellular ODN uptake. This result indicates that the glucose residue at the 5'-end does not result in an improvement of the penetration of the ODN through the cellular membrane.

The 5' glucose conjugation diminished the intrinsic CpG ODNs immunoestimulatory effect

An additional limitation associated to the use of ODNs is the nonspecific stimulation of the immune response, which may result in undesired cytotoxic effects challenging their in vivo 
applications. In particular synthetic ODN containing unmethylated cytosine-guanosine motifs $(\mathrm{CpG})$ have been described as potent immunoestimulatory. ${ }^{[31]}$ It is important to note that GEM 91 ODN contains a CpG dinucleotide located closer to the 5'-end and it has been shown that such dinucleotide located closer to the 5 '-end is critical for induction of the immune responses ${ }^{[32]}$ and the blockage of the ODN $5^{\prime}$ end results in loss of the immunostimulatory effect. $^{[33]}$ To determine the effect of the conjugation of the glucose molecule to the 5'-end of GEM 91 in the stimulation of the innate immune response, we directly quantified the amount of IL-10 mRNA expression by real time quantitative RTPCR. For this purpose human Namalwa cells, which has been shown to express IL-10 in response to CpG ODNs, were used. ${ }^{[34]}$ IL-10 mRNA amount was 50 and 40 fold higher in the Namalwa cells treated with the immunostimulatory OD2006 (used as positive control) and the Gluc-GEM 91, respectively, than in untreated cells (Figure 9). In contrast, cell treatment with Gluc-GEM 91 (PS) resulted in a $87.2 \%$ decrease of IL-10 mRNA level expression compared to cells treated with GEM 91 (PS). These results indicate that blockage of the 5'-end with a glucose results in a decrease of the TLR9-mediated ODN immunostimulatory activity in accordance with previous data. ${ }^{[33]}$

\section{Discussion}

A potent antisense drug should be highly resistant to nucleases, to exhibit high affinity for the target mRNA and favourable pharmacokinetics. These properties can be achieved by the introduction of chemical modifications. Most of the ODNs being used now in clinical trials contain a phosphorothioate or morpholino backbone instead of the phosphodiester. Additionally, chemical conjugation or linking reporter groups to ODNs has tremendous therapeutic potential not only to improve the existing antisense ODN biological properties but also to impart entirely new ones. Diverse reporter groups like peptides, vitamins, 
hormones, growth factors, enzymes, carbohydrates, lipophilic molecules, polymers, fluorescent dyes, luminescent groups, spin labels, metal complexes and nanoparticles have been conjugated to ODNs to obtain conjugates for various applications. Many synthetic carbohydrate-ODN conjugates have been synthesized, but most of them have not yet been evaluated in cell-based assays. ${ }^{[35]}$ Information on the stability of ODNs, and their structurally modified analogues, in the biological milieu is important not only for cell culture studies but also, from a pharmaceutical viewpoint, in designing effective delivery systems for ODNs as therapeutic agents.

Natural phosphodiester ODNs are quickly digested by nucleases, it appears that the bulk of biologically significant nucleolytic activity in serum is $3^{\prime}$ exonuclease ${ }^{[7 b]}$ however within the cell nucleolitic activity is both $3^{\prime}$ and $5^{\prime}$ exonuclease. ${ }^{[7 a]}$ As expected, our results indicated that in cell culture medium containing heat inactivated serum GEM 91 (PS) and Gluc-GEM 91 (PS) were more stable than GEM 91 (PO) and Gluc-GEM 91 (PO). We found no differences in stability between the glucose conjugated and unconjugated ODNs in serum. However, these ODNs attached to glucose in its 5 -end could be even more stable in vivo than unconjugated ODNs since modification at the 5'-end may protect them from 5' exonuclease digestion in vivo. Our results also indicated that the 5' glucose conjugation did not lead to an improvement of the ODN cellular uptake (Figure 8). These results mostly agree with previous observations reporting that cellular uptake was hardly improved by the conjugation of glucose monomers just when linked through a long tetraethylene glycol spacer, ${ }^{[19]}$ showing that a 15 to 18 atoms distance between the glucose and the ODN should be kept to achieve a more efficient cellular internalization. This observation should be considered for further optimization of antisense Gluc-ODNs. The antiviral activity of GEM 91 (PO), Gluc-GEM 91 (PO), GEM 91 (PS) and Gluc-GEM 91 (PS) was tested in acutely HIV-1 infected cells using two different CD4 ${ }^{+}$cell lines, Jurkat and U87-CD4 ${ }^{+}-\mathrm{CXCR} 4^{+}$, which are susceptible to HIV-1 infection and allow a high level of 
viral replication. Our results showed that in contrast to the PS derivatives, the GEM 91 (PO) and Gluc-GEM 91 (PO) exhibited antiviral activity only when they are delivered by transfect agents to culture cells (Figure 5A). The most likely explanation is that GEM 91 (PO) and Gluc-GEM 91 (PO) are not resistant enough in the cell or the culture medium and the potential problem of nuclease degradation of the ODNs may conceivable be overcome by delivering them using transfection agents, entering within the nucleus more efficiently and therefore resulting in significant inhibition of viral particles production. It is remarkable that the conjugation of glucose at the 5'-end of GEM 91 (PS) or GEM 91 (PO) resulted in similar anti HIV-1 activity to that of its unconjugated molecule, indicating that the glucose residue at the 5 -end does not result in a modification of the mechanism of action of the ODNs challenging their antiviral activity. The lack of correlation between the in vitro dimerisation effects and the anti-HIV activities in cell culture assays clearly indicate that the latest is mainly due to the ODNs interference with other steps of the HIV-1 particles production process. ODNs cell induced toxicity is also an important factor that could lead to an overestimation of the antiviral ODN effect when assessing it by a p24 assay. In the conditions used in this study we have not detected any cytotoxicity as monitored by trypan blue dye exclusion (data not shown).

Previous studies have demonstrated that differences in immunostimulatory activity of 3'and 5 '-conjugates are due to the requirement of 5 '-end accessibility for TLR9-mediated immune responses, but not as a result of their differences in cellular uptake, as both types of conjugates are taken up by cells to the same extent. ${ }^{[33]}$ Further, these studies showed that conjugation of a mono, di, tetra, or oligonucleotide through $5^{\prime}-5^{\prime}$ linkage or a fluorescein moiety, but not a phosphorothioate group, at the $5^{\prime}$-end significantly reduces TLR9-mediated immune response. ${ }^{[33]}$ These results together with our present study suggest that an accessible 5 '-end of ODN is required for TLR9- mediated immune responses and conjugation of moieties like peptides or glucose at the $5^{\prime}$-end of ODN 
results in loss of TLR9-mediated immune responses. On the other hand, it is likely that TLR9 activated immune response by the CpG motif in GEM 91 was responsible for the observed increases in viral load, ${ }^{[24]}$ being biologically active even in ODN (PS). Our data clearly indicate that conjugation of glucose to the 5'-end of GEM 91 (Gluc-GEM 91) decreases immune response through TLR9 while it is taking up well by cells, hybridizes to its complementary nucleic acid target and maintain an unaffected anti HIV-1 activity. Presently several antisense ODN (PS) containing CpG motifs are in human clinical trials for various diseases and indications. Our data suggests that conjugation of a molecule of glucose at the 5'-end could act as "immunosupressor" and thereby reduce toxic effects while still allowing proper binding to its target sequence, and biological activity.

In conclusion, the results presented here demonstrate that the 5' Gluc-ODN conjugation decreases the innate cellular response associated to the recognition of the 5'-end in CpG ODNs, and therefore the undesired side effects associated to such response, at the time that does not interfere with the biological activity of the ODNs, proposing these conjugates are of value as antisense agents.

\section{Experimental Section}

ODNs and RNA synthesis

All ODNs were synthesized on $1 \mu \mathrm{mol}$ scale using standard phosphoramidite chemistry. GEM 91 ODN series used in this study were: GEM 91 (PO) 5'CTCTCGCACCCATCTCTCTCCTTCT-3', which corresponds to the unmodified ODN; Gluc-GEM 91 (PO), contained a glucose molecule covalently linked to its 5'-end; GEM 91 (PS) and Gluc-GEM 91 (PS) are the corresponding totally substituted phosphorothioate ODNs. The 5 ' glucose conjugation was obtained as previously described. ${ }^{[36]}$ The Random25 ODN, a 25 nt long random sequence, and pLCX-25 (5'- 
GACGTCGAGTGCCCGAAGGATAGCT-3') a $25 \mathrm{nt}$ long ODN which is not complementary to any known cellular or HIV-1 gene, were used as negative controls. The DNA template for the synthesis of the HIV-1 5'-UTR genomic RNA fragment was obtained by PCR amplification of the pNL4-3 plasmid, ${ }^{[30]}$ using the primers 5'-T7pNL4-3: 5'TAATACGACTCACTATAGGGTCTCTCTGGTTAG-3' (T7 promoter sequence is indicated in bold), and 3' pNL4-3-gag 5'-GCTTAATACCGACGCTCTC-3'. HIV-1 5'-UTR genomic RNA fragment was obtained by in vitro transcription as previously described. ${ }^{[37]}$

\section{Antisense ODN stability assay}

A total of $3 \mathrm{nmol}$ of each ODN were resuspended in of $30 \mu \mathrm{L}$ sterile $\mathrm{ddH}_{2} \mathrm{O}$ and incubated with $70 \mu \mathrm{L}$ Dulbecco's modified Eagle's medium (DMEM) supplemented with $10 \%$ fetal bovine serum (FBS) at $37^{\circ} \mathrm{C}$. Aliquots of $10 \mu \mathrm{L}$ were withdrawn at each time point, added to a mix of $2 \mu \mathrm{L}$ of $10 \mathrm{X}$ TE and $10 \mu \mathrm{L}$ of $2 \mathrm{X}$ loading buffer $(0.1 \%$ bromophenol blue, $1.2 \mathrm{X}$ TBE and 10\%, glycerol), and snap-frozen on dry ice immediately. Samples were thawed and run on a $15 \%$ nondenaturing $1 \mathrm{X}$ TBE polyacrylamide gel at $100 \mathrm{~V}$ for $75 \mathrm{~min}$ and stained with a 1:10000 dilution of GelStar ${ }^{\circledR}$ Nucleic Acid Gel Stain (Lonza, Rockland, ME) in 1X TBE buffer for $30 \mathrm{~min}$. Gels were scanned using Typhoon 9400 Phosphorimager/Fluorescence Imager and quantified with Image Quant software $5.2^{\odot}$ (GE Healthcare; Chalfont ST. Giles, UK).

In vitro RNase $H$ cleavage assay

RNase H digestion assays were essentially as described in Reyes-Darias et al. (2012). ${ }^{[28 b]}$ Viral RNA transcript was incubated separately with each different concentrations of each ODN for $30 \mathrm{~min}$ at $37^{\circ} \mathrm{C}$. Subsequently, $5 \mathrm{U}$ of RNase $\mathrm{H}$ was added to the mixtures and incubated at $37^{\circ} \mathrm{C}$ for $20 \mathrm{~min}$. The reactions were quenched with equal volumes of $2 \mathrm{X}$ formamide loading buffer and loaded onto a $7 \mathrm{M}$ urea $6 \%$ polyacrylamide denaturing gel in 
1X TBE buffer. Electrophoresis was followed at $20 \mathrm{~mA}$ for approximately $90 \mathrm{~min}$, and gels were dried and analysed as described above.

Inhibition of HIV-1 RNA dimerisation by ODNs

HIV-1 RNA dimerisation reactions were performed as previously described ${ }^{[38]}$ in the presence or absence of $100 \mathrm{pmol}$ of unlabelled antisense ODN. Samples were resolved in $1 \%$ agarose gels in $1 \mathrm{X}$ TBM buffer $(0.5 \mathrm{X}$ Tris-borate, $0.1 \mathrm{mM} \mathrm{MgCl})$, and gels were visualized and quantified as described above. The dimerisation efficiency was calculated as [dimmer $\times 100 /($ dimer + monomer)]. Data are expressed at the mean \pm standard deviation of two independent experiments.

\section{Cell culture}

The human glioblastoma U87-CD4 ${ }^{+}-\mathrm{CXCR} 4^{+}$cell line, stably expressing CD4 and the chemokine receptor CXCR4, was grown in DMEM supplemented with $10 \% \mathrm{FBS}, 50 \mu \mathrm{g} / \mathrm{mL}$ gentamycin (Sigma Chemical Co. St Louis, MO), 1 mM sodium pyruvate (Sigma), 2 mM Lglutamine (Sigma), $300 \mu \mathrm{g} / \mathrm{mL} \mathrm{G418} \mathrm{(Sigma)} \mathrm{and} 1 \mu \mathrm{g} / \mathrm{mL}$ puromycine (Sigma). The human embryonic kidney HEK 293T cell line was maintained in DMEM supplemented with 10\% FBS, $100 \mu \mathrm{g} / \mathrm{mL}$ streptomycin (Sigma), $4 \mathrm{mM} \mathrm{L-glutamine} \mathrm{and} 1 \mathrm{mM}$ sodium pyruvate. Human Burkitt lymphoma cell line Namalwa was maintained as suspension culture in RPMI 1640 medium supplemented with 10\% FSB, 2 mM L-glutamine and 50 $\mu \mathrm{g} / \mathrm{mL}$ gentamycin (Sigma). Cells were maintained at $37^{\circ} \mathrm{C}$ in a humidified atmosphere with $5 \% \mathrm{CO}_{2}$.

\section{HIV-1 inhibition of viral particles production assays}

For post-integrative viral inhibition assay U87-CD4 ${ }^{+}-\mathrm{CXCR} 4^{+}, 1 \times 10^{5}$ cells/well were seeded in $0.5 \mathrm{~mL}$ of DMEM in $24-w e l l$ culture plates and incubated at $37^{\circ} \mathrm{C}$ for $24 \mathrm{~h}$ before 
co-transfection. The following day cells were co-transfected with 500 pmol $(1 \mu \mathrm{M})$ of ODN and $100 \mathrm{ng}$ of pNL4-3 plasmid complexed together with $1 \mu \mathrm{L}$ Fugene HD (Roche; Mannheim, Germany). After 6 hours, the transfection mixture was replaced with $1 \mathrm{~mL}$ of fresh growth medium, and cells were further incubated at $37^{\circ} \mathrm{C}$ for two days before p24 determination.

For pre-integrative viral inhibition assays, U87-CD4 ${ }^{+}-\mathrm{CXCR} 4^{+}$cells were seeded in $0.5 \mathrm{ml}$ of DMEN at a density of $8 \times 10^{5}$ cells/well in 24 -well culture plates and incubated at $37^{\circ} \mathrm{C}$ for 24 hours before infection. Cells were infected by the addition of 0.4 ng of p24 HIV-1 type pNL4-3 in a total volume of $200 \mu \mathrm{L}$ of medium. After 3 hours incubation at $37^{\circ} \mathrm{C}$, cells were washed and treated with the individual ODN at $1 \mu \mathrm{M}$ concentration. HIV-1 replication was monitored after five days at the cellular level by syncytia formation by light microscopy and viral p24 antigen in $200 \mu \mathrm{L}$ culture supernatants using the Greenscreen HIV-1 Ag Enzyme Immunoassay (EIA; Bio-Rad, Hercules, CA) following manufacturer instructions. Alternatively, Jurkat cells $\left(5 \times 10^{5} / \mathrm{mL}\right)$ were infected under the same conditions for long term antiviral assays. Infected cells were treated with GEM 91 and Gluc-GEM 91 at concentrations $1,2,4$ and $8 \mu \mathrm{M}$, and split into separate flasks with fresh medium to $5 \times 10^{5}$ cells/mL every 3 or 4 days. The p24 antigen levels in the supernatant were quantified at the indicated times. Cell viability was detected by trypan blue exclusion assay. The percentage of viable cells is calculated at different days after transfection.

Virus stocks for infection were produced by transfection of HEK 293 T cells $\left(6 \times 10^{5}\right.$ cells per well in 6-well plates) with $4 \mu \mathrm{g}$ of pNL4-3 using Lipofectamine 2000 transfectant agent (Life Technologies; Oslo, Norway). Supernatants were collected at $48 \mathrm{~h}$ after transfection, centrifuged at $3000 \mathrm{~g}$ for $5 \mathrm{~min}$ to remove cell debris, clarified by passage through a 0.22 $\mu \mathrm{m}$ syringe filter to remove residual cellular contaminants and frozen at $-80^{\circ} \mathrm{C}$ until needed. 


\section{Cellular uptake of ODNs}

Human U87-CD4 ${ }^{+}-\mathrm{CXCR} 4^{+}$and HEK 293 cell lines were independently incubated with 10 pmol of 3 '-end ${ }^{32} \mathrm{P}$-labeled GEM 91 (PS) or Gluc-GEM 91 (PS) at $37^{\circ} \mathrm{C}$ for 2,4 and $8 \mathrm{~h}$. After incubation, extracellular ${ }^{32} \mathrm{P}$-labeled oligonucleotide was removed by digestion for 2 min with $300 \mathrm{U} / \mathrm{mL}$ of DNase I in $50 \mathrm{mM}$ Tris- $\mathrm{HCl} \mathrm{pH} \mathrm{7.6,} 10 \mathrm{mM} \mathrm{MgCl}_{2}$ and washed three times with phosphate-buffered saline (PBS). Cells were then trypsinized, collected in $1 \mathrm{~mL}$ of PBS and centrifuged at $1000 \mathrm{~g}$ for $5 \mathrm{~min}$. The cell pellet was lysed with $500 \mathrm{~mL}$ of 10 $\mathrm{mM}$ Tris- $\mathrm{HCl} \mathrm{pH} \mathrm{7.4,} 150 \mathrm{mM} \mathrm{NaCl}$ and1\% SDS, and centrifuged at $3000 \mathrm{~g}$ for $15 \mathrm{~min}$. The supernatant was collected in microcentrifuge tubes and the ODN was precipitated by adding $50 \mu \mathrm{L}$ of $5 \mathrm{M} \mathrm{NaCl}$ and $1 \mathrm{~mL}$ of cold $100 \%$ ethanol. After $1 \mathrm{~h}$ at $-80^{\circ} \mathrm{C}$, the solution was centrifuged at $12000 \mathrm{~g}$ for $15 \mathrm{~min}$. The supernatant was removed and the pellet was air-dried. Samples were dissolved in $20 \mu \mathrm{L}$ of a solution containing $10 \mathrm{mM}$ Tris- $\mathrm{HCl}$ and 50 $\mathrm{mM} \mathrm{NaCl}$ and radioactivity was quantified using a QuickCount QC-4000/XER Benchtop Radioisotope Counter (Bioscan, Inc., Washington DC). Uptake was calculated as the proportion of the pellet-associated radioactive counts per minute $(\mathrm{cpm})$ with respect to the total cpm input.

\section{Quantitative real-time RT-PCR}

Real-time RT-PCR assays were performed $24 \mathrm{~h}$ after treatment of cells with ODNs. Namalwa cells $\left(2 \times 10^{6}\right.$ cells $\left./ \mathrm{mL}\right)$ were stimulated with $2.5 \mu \mathrm{M}$ of GEM 91 , Gluc-GEM 91 or the immunostimulatory CpG OD2006 (5'-TCGTCGTTTTGTCGTTTTGTCGTT-3') used as positive control. Cells were harvested $24 \mathrm{~h}$ after ODN treatment and total RNA was extracted using Trizol reagent (Invitrogen, Carlsbad, CA) according to the manufacturer's instructions. To remove potentially contaminating genomic DNA, all RNA samples were digested with $1 \mathrm{U}$ of RNase-free RQ1 DNase at $37^{\circ} \mathrm{C}$ for 30 min followed by phenolchloroform extraction. RNA was dissolved in $30 \mu \mathrm{L}$ of nuclease-free water and stored at - 
$80^{\circ} \mathrm{C}$. Total RNA $(1 \mu \mathrm{g})$ was reverse transcribed using the High-Capacity cDNA Reverse Transcription Kit (Applied Biosystems) and random hexamers, according to the manufacturer's instructions. The cDNA was used as a template for quantitative qRT-PCR analysis to measure the relative amount of IL-10 mRNA using iTaq Fast SYBR Green Supermix with ROX (Bio-Rad), in combination with the ABI 7000 sequence detection system (Applied Biosystems, Foster City, CA) according to the manufacturer's instructions. The IL-10 RT-PCR was done with primers: forward, 5'-TCGGTGATGGTCTCTTCCTC-3' and reverse, 5'-CGTCGCAATAAACCGTACCT-3' amplifying a 237-bp fragment. Gene expression was normalised to the GAPDH expression levels. The calibrator sample in realtime PCR was the cDNA from untransfected Namalwa cells. Data was analysed using the comparative cycle threshold (Ct) method, as described. ${ }^{[39]}$

\section{Acknowledgements}

We would like to thank Vicente Augustin Vacas for excellent technical assistance. This work was supported by grant PIF200620F0143 from the CSIC.

\section{References}

[1] a) D. A. Braasch, D. R. Corey, Biochemistry 2002, 41, 4503-4510; b) T. Da Ros, G. Spalluto, M. Prato, T. Saison-Behmoaras, A. Boutorine, B. Cacciari, Curr. Med. Chem. 2005, 12, 71-88; c) N. M. Dean, C. F. Bennett, Oncogene 2003, 22, 9087-9096; d) C. Helene, J. J. Toulme, Biochim. Biophys. Acta 1990, 1049, 99-125; e) A. S. Retter, J. L. Gulley, W. L. Dahut, Cancer Biol. Ther. 2004, 3, 371-376.

[2] H. Sierakowska, M. J. Sambade, S. Agrawal, R. Kole, Proc. Natl. Acad. Sci. USA 1996, 93, $12840-12844$.

[3] J. A. Saonere, J. Med. Genet. and Genom. 2011, 3, 6.

[4] a) R. F. Azad, V. B. Driver, K. Tanaka, R. M. Crooke, K. P. Anderson, Antimicrob. Agents Chemother. 1993, 37, 1945-1954; b) J. B. Opalinska, A. M. Gewirtz, Nat. Rev. Drug Discov. 2002, 1, 503-514.

[5] E. S. Gragoudas, A. P. Adamis, E. T. Cunningham, Jr., M. Feinsod, D. R. Guyer, V. I. S. i. O. N. C. T. Group, N. Engl. J. Med. 2004, 351, 2805-2816.

[6] G. Sinha, Nat. Biotechnol. 2013, 31, 179-180. 
[7] a) J. M. Dagle, D. L. Weeks, J. A. Walder, Antisense Res. and Dev. 1991, 1, 11-20; b) P. S. Eder, J. A. Walder, J. Biol. Chem. 1991, 266, 6472-6479.

[8] a) S. Agrawal, J. Goodchild, Tetrahedron Lett. 1987, 28, 3539-3542; b) K. R. Blake, A. Murakami, S. A. Spitz, S. A. Glave, M. P. Reddy, P. O. Ts'o, P. S. Miller, Biochemistry 1985, 24, 6139-6145; c) H. Matzura, F. Eckstein, Eur. J. Biochem. 1968, 3, 448-452.

[9] a) P. J. Furdon, Z. Dominski, R. Kole, Nucleic Acids Res. 1989, 17, 9193-9204; b) C. A. Stein, C. Subasinghe, K. Shinozuka, J. S. Cohen, Nucleic Acids Res. 1988, 16, 32093221.

[10] D. A. Braasch, S. Jensen, Y. Liu, K. Kaur, K. Arar, M. A. White, D. R. Corey, Biochemistry 2003, 42, 7967-7975.

[11] M. Manoharan, Antisense Nucleic Acid Drug. Dev. 2002, 12, 103-128.

[12] J. P. Leonetti, B. Rayner, M. Lemaitre, C. Gagnor, P. G. Milhaud, J. L. Imbach, B. Lebleu, Gene 1988, 72, 323-332.

[13] J. Haralambidis, L. Duncan, K. Angus, G. W. Tregear, Nucleic Acids Res. 1990, 18, 493-499.

[14] C. MacKellar, D. Graham, D. W. Will, S. Burgess, T. Brown, Nucleic Acids Res. 1992, 20, 3411-3417.

[15] C. Boiziau, J. J. Toulme, Biochimie 1991, 73, 1403-1408.

[16] F. Ramírez, J. F. Marecek, S. I. Tu, T. V. Kantor, H. Okazaki, Eur. J. Biochem. 1982, 121, 275-279.

[17] E. Kuyl-Yeheskiely, C. M. Dreef-Tromp, A. Geluk, G. A. van der Marel, J. H. van Boom, Nucleic Acids Res. 1989, 17, 2897-2905.

[18] A. Jaschke, J. P. Furste, E. Nordhoff, F. Hillenkamp, D. Cech, V. A. Erdmann, Nucleic Acids Res. 1994, 22, 4810-4817.

[19] B. Ugarte-Uribe, S. Pérez-Rentero, R. Lucas, A. Aviñó, J. J. Reina, I. Alkorta, R. Eritja, J. C. Morales, Bioconjug. Chem. 2010, 21, 1280-1287.

[20] E. Vengut-Climent, M. Terrazas, R. Lucas, M. Arévalo-Ruiz, R. Eritja, J. C. Morales, Bioorg. Med. Chem. Lett. 2013, 23, 4048-4051.

[21] S. Agrawal, J. Y. Tang, Antisense Res. Dev. 1992, 2, 261-266.

[22] M. A. Muesing, D. H. Smith, C. D. Cabradilla, C. V. Benton, L. A. Lasky, D. J. Capon, Nature 1985, 313, 450-458.

[23] J. Lisziewicz, D. Sun, F. F. Weichold, A. R. Thierry, P. Lusso, J. Tang, R. C. Gallo, S. Agrawal, Proc. Natl. Acad. Sci. USA 1994, 91, 7942-7946.

[24] S. Agrawal, R. R. Martin, J. Immunol. 2003, 171, 1621; author reply 1621-1622.

[25] S. Agrawal, Biochim. Biophys. Acta 1999, 1489, 53-68.

[26] H. Hemmi, O. Takeuchi, T. Kawai, T. Kaisho, S. Sato, H. Sanjo, M. Matsumoto, K. Hoshino, H. Wagner, K. Takeda, S. Akira, Nature 2000, 408, 740-745.

[27] O. Equils, M. L. Schito, H. Karahashi, Z. Madak, A. Yarali, K. S. Michelsen, A. Sher, M. Arditi, J. Immunol. 2003, 170, 5159-5164.

[28] a) J. L. Clever, T. G. Parslow, J. Virol. 1997, 71, 3407-3414; b) J. A. Reyes-Darias, F. J. Sánchez-Luque, A. Berzal-Herranz, Virus Res. 2012, 169, 63-71.

[29] a) R. Cosstick, F. Eckstein, Biochemistry 1985, 24, 3630-3638; b) L. A. LaPlanche, T. L. James, C. Powell, W. D. Wilson, B. Uznanski, W. J. Stec, M. F. Summers, G. Zon, Nucleic Acids Res. 1986, 14, 9081-9093.

[30] A. Adachi, H. E. Gendelman, S. Koenig, T. Folks, R. Willey, A. Rabson, M. A. Martin, J. Virol. 1986, 59, 284-291.

[31] a) A. M. Krieg, Annu. Rev. Immunol. 2002, 20, 709-760; b) A. M. Krieg, A. K. Yi, S. Matson, T. J. Waldschmidt, G. A. Bishop, R. Teasdale, G. A. Koretzky, D. M. Klinman, Nature 1995, 374, 546-549.

[32] M. R. Putta, L. Bhagat, D. Wang, F. G. Zhu, E. R. Kandimalla, S. Agrawal, ACS Med. Chem. Lett. 2013, 4, 302-305. 
[33] a) E. R. Kandimalla, L. Bhagat, D. Yu, Y. Cong, J. Tang, S. Agrawal, Bioconjug. Chem. 2002, 13, 966-974; b) D. Yu, Q. Zhao, E. R. Kandimalla, S. Agrawal, Bioorg. Med. Chem. Lett. 2000, 10, 2585-2588.

[34] M. Henault, L. N. Lee, G. F. Evans, S. H. Zuckerman, J. Immunol. Methods 2005, 300, 93-99.

[35] a) H. Lonnberg, Bioconjug. Chem. 2009, 20, 1065-1094; b) N. Spinelli, E. Defrancq, F. Morvan, Chem. Soc. Rev. 2013, 42, 4557-4573; c) T. S. Zatsepin, T. S. Oretskaya, Chem. Biodivers. 2004, 1, 1401-1417.

[36] J. C. Morales, J. J. Reina, I. Díaz, A. Aviñó, P. M. Nieto, R. Eritja, Chemistry 2008, 14, 7828-7835.

[37] A. Barroso-delJesus, M. Tabler, A. Berzal-Herranz, Antisense Nucleic Acid Drug Dev. 1999, 9, 433-440.

[38] F. J. Sánchez-Luque, J. A. Reyes-Darias, E. Puerta-Fernández, A. Berzal-Herranz, Molecules 2010, 15, 4757-4772.

[39] K. J. Livak, T. D. Schmittgen, Methods 2001, 25, 402-408. 


\section{Figure Legends}

Figure 1. GEM 91 ODN. A) Sequence of GEM 91 and the targeted region in the 5'-end of the HIV-1 RNA genome. B) Backbone modifications and glucose molecule conjugated to GEM 91 ODN.

Figure 2. Serum stability of ODNs. A representative polyacrylamide gel electrophoresis of each ODN incubated in DMEM medium supplemented with 10\% FBS is shown. Incubation times are indicated on top. A collection of synthetic ODN of 45, 25 and 19 mer was used as size marker (Lane M), as indicated to the left. Gels are a representative of three independent experiments.

Figure 3. In vitro RNase $\mathrm{H}$ cleavage assays. Representative autoradiograph of a $7 \mathrm{M}$ urea polyacrylamide gel resolving the RNase H-cleaved RNA fragments of the HIV-1 5'-UTR RNA in the presence of GEM 91 (PS), Gluc-GEM 91 (PS), GEM 91 (PO) and Gluc-GEM 91 (PO) ODNs. Internally ${ }^{32}$ P-labelled HIV-1 5'-UTR RNA fragment was incubated to increasing concentrations of different antisense ODNs (indicated at the top of each lane). Lane control: undigested full length ${ }^{32} \mathrm{P}$-labelled HIV-1 5'-UTR transcript. Century marker (Ambion) was used as RNA size marker (lane M).

Figure 4. Inhibition of viral RNA dimerisation. A constant amount of ${ }^{32} \mathrm{P}$-labeled HIV-1 genomic RNA fragment 1-345 (5 nM) was incubated in high-salt conditions in the presence of unlabeled ODNs. The monomeric and dimeric RNA species were fractionated by electrophoresis on $1 \%$ native agarose gels. The dimer and monomer species are indicated by arrowheads to the left of the gel. Lane 1; Control monomer RNA (low-salt conditions). Lane 2; Control dimeric RNA (high-salt conditions) in the absence of ODN. Dimerisation 
rate, indicated at the bottom, represents the average of two independent experiments \pm standard deviation. Statistically significant differences were obtained with all GEM 91 ODN series as compared to the control (ANOVA, $p<0.001$ ).

Figure 5. Antiviral activity of glucose conjugated and unconjutated antisense ODNs. A) The bar graph shows the post-integrative HIV-1 inhibition obtained by measuring the amount of p24 antigen levels in the supernatant of U87-CD4 ${ }^{+}-\mathrm{CXCR} 4^{+}$cell cultures 2 days post co-transfection with $100 \mathrm{ng}$ of proviral DNA and $500 \mathrm{ng}$ of the indicated ODN. B) U87CD4CXCR4 cells were infected with $0.4 \mathrm{ng}$ of p24 HIV-1 type pNL4-3. After 3 hours, cells were washed and treated with $1 \mu \mathrm{M}$ concentration ODN. Cells were incubated for 5 days, and then p24 virus antigen expression was measured. pLCX-25 and Random-25 ODNs were used as negative controls. The data are the mean of three independent experiments, each performed in duplicate, \pm standard deviation.

Figure 6. Syncytium formation inhibition by the anti HIV-1 ODNs. Microscopic view of U87-CD4 ${ }^{+}-\mathrm{CXCR} 4^{+}$culture cells two days after co-transfected with plasmid pNL4-3 and PLCX-25, Random-25, GEM 91 (PO), Gluc-GEM 91 (PO), GEM 91 (PS) and Gluc-GEM 91 (PS). Syncytium are indicated by arrowheads.

Figure 7. Long-term ODNs antiviral activity. The bar graph shows the HIV-1 infection course of Jurkat cells treated with 1, 2, 4 and $8 \mu \mathrm{M}$ of GEM 91 (PS) or Gluc-GEM 91 (PS) ODNs. Amount of viral particles was measured as p24 antigen in the supernatant, after 2, $4,6,10,15,20$ and 30 days. The data represent the mean of two independent experiments, each performed in duplicate, \pm standard deviation. 
Figure 8. Cellular ODNs uptake. HEK 293T cells were incubated with ${ }^{32}$ P-GEM 91 (PS) or ${ }^{32} \mathrm{P}$-Gluc-GEM 91 (PS) at the indicated times. ODN uptake was calculated as the ratio of pellet-associated radioactive counts per minute (CPM) compared with total input. The uptake is represented by the percentage of ${ }^{32} \mathrm{P}$-GEM 91 (PS) or ${ }^{32} \mathrm{P}$-Gluc-GEM 91 (PS) remaining inside the cell. Data are the mean of two independent experiments which were carried out in duplicate \pm standard deviation.

Figure 9. Induction of IL-10 mRNA in Namalwa cell cultures in the presence of ODNs. The bar graph shows the relative amount of IL-10 mRNA measured by RT-qPCR from total RNA isolated from Namalwa cell cultures immunoestimulated with GEM 91 (PS), Gluc-GEM 91 (PS) and OD2006 as positive control. Expression levels were normalized to the cellular GAPDH gene. Data represent the mean of two independent experiments \pm standard deviation. 


\section{Table of contents}

Efficient inhibition of HIV-1 viral load by the 5' glucose conjugated GEM 91 antisense ODN. The glucose conjugation significantly reduces the immunostimulatory effect of the ODN without challenging its potent anti-HIV-1 activity. This provides an optimization strategy of ODNs for therapeutic applications. 
Figure 1

A)

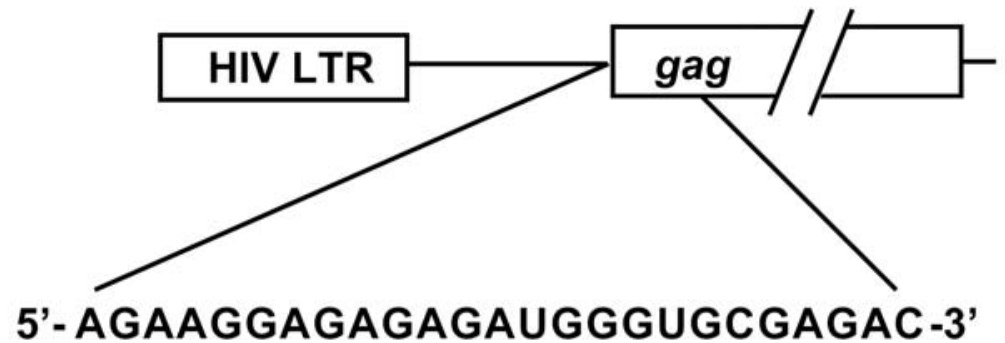

GEM 913 '- TСT TCCTCTCTCTACCCACGCTCTG-5'

B)

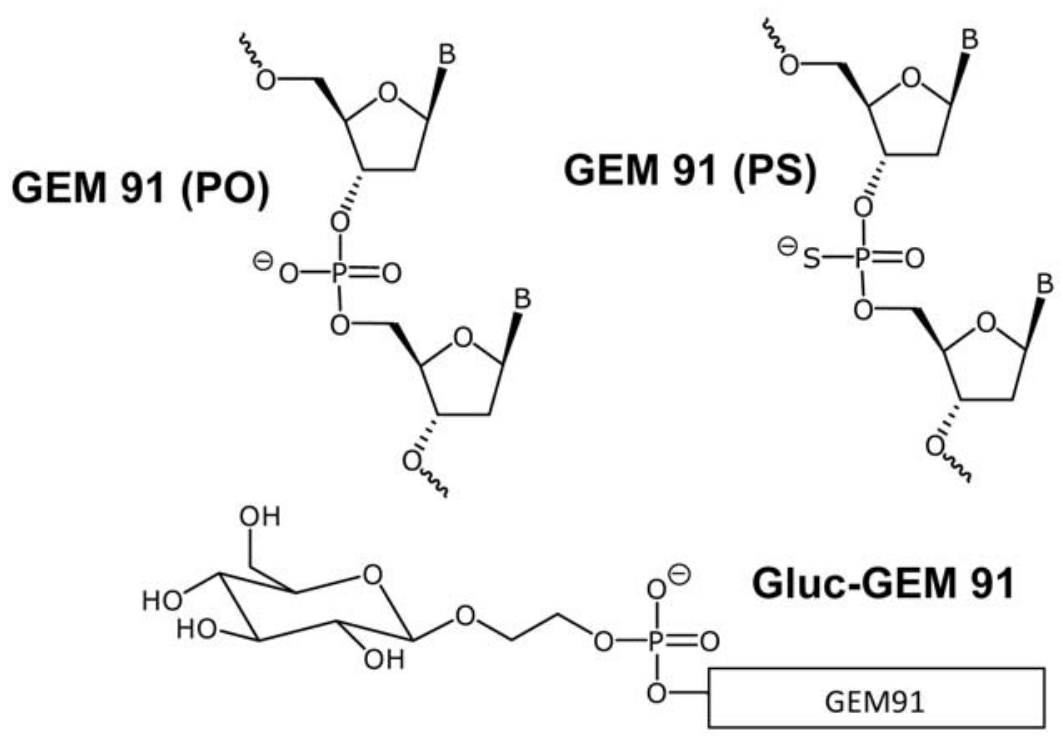


Figure 2

Serum incubation ( $\mathrm{min}$ )

Serum incubation (h)

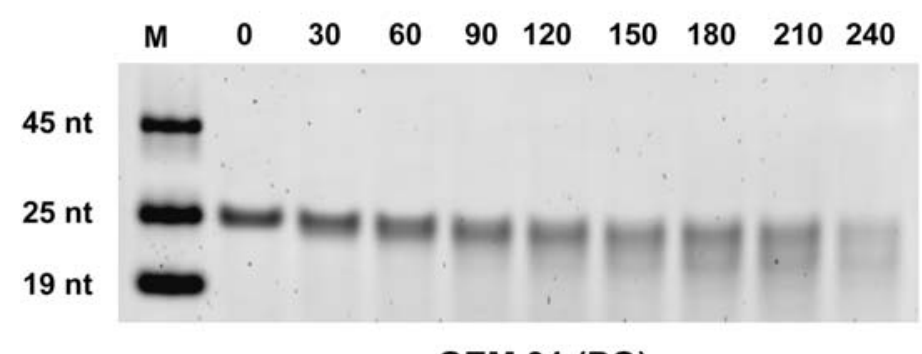

GEM 91 (PO)

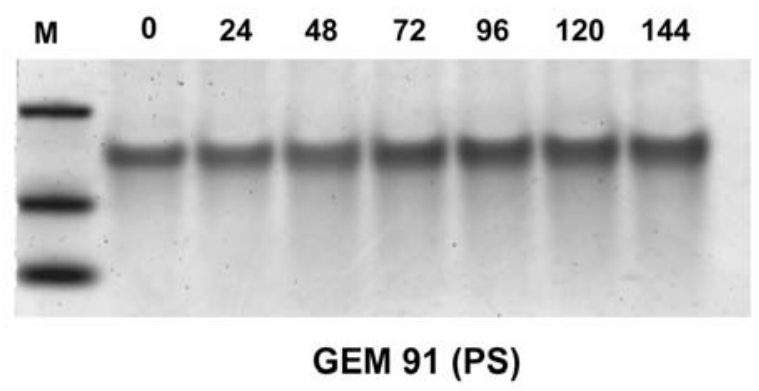

$45 \mathrm{nt}$

25 nt

$19 \mathrm{nt}$

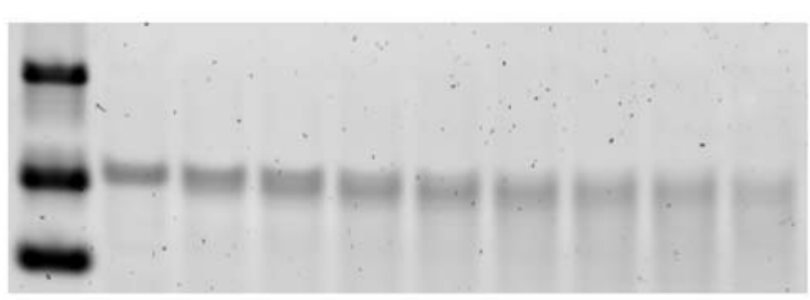

Gluc-GEM 91 (PO)

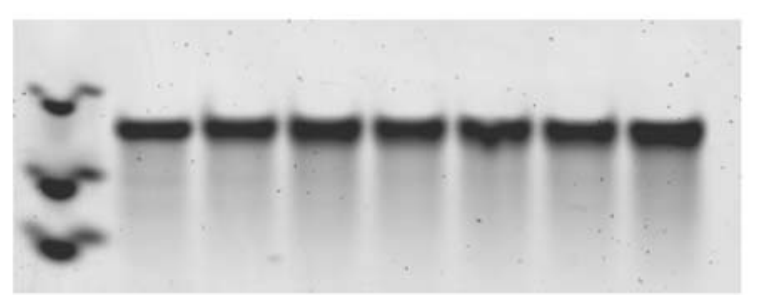

Gluc-GEM 91 (PS) 
Figure 3

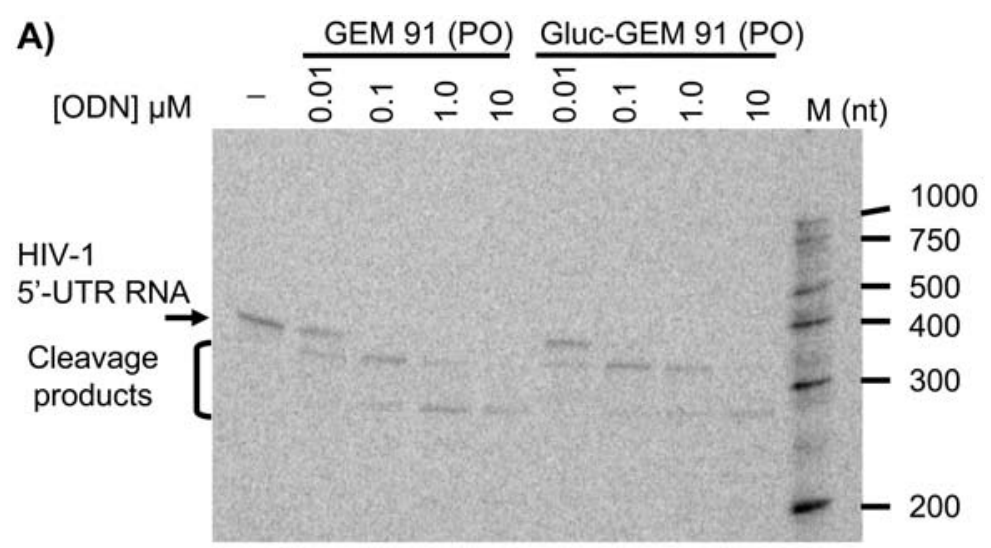

B)

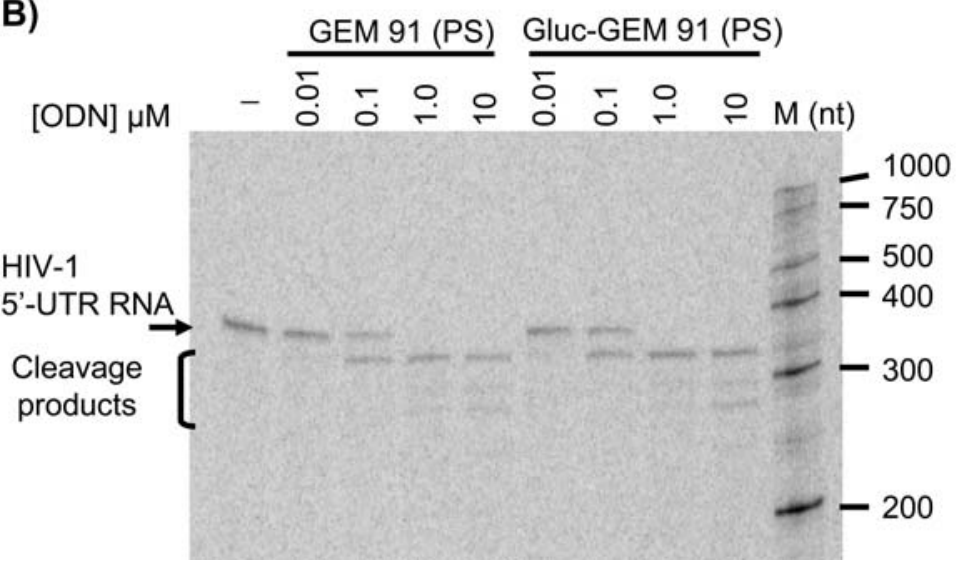


Figure 4

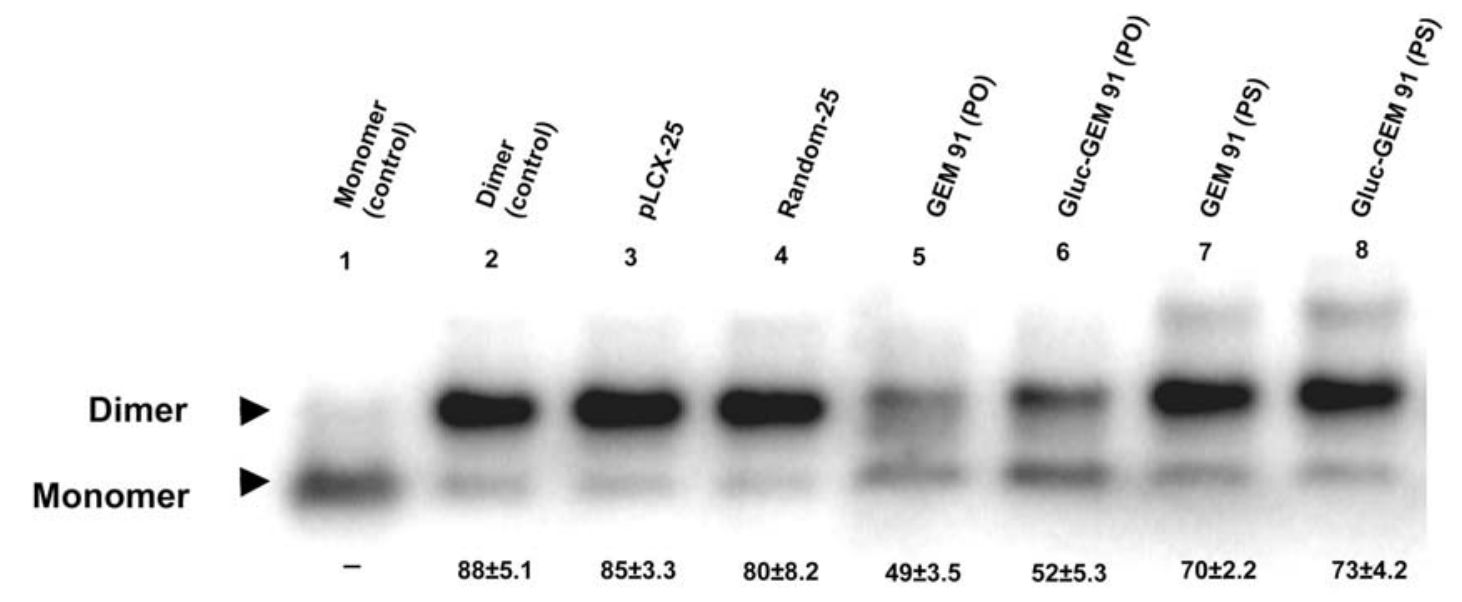


Figure 5

A)

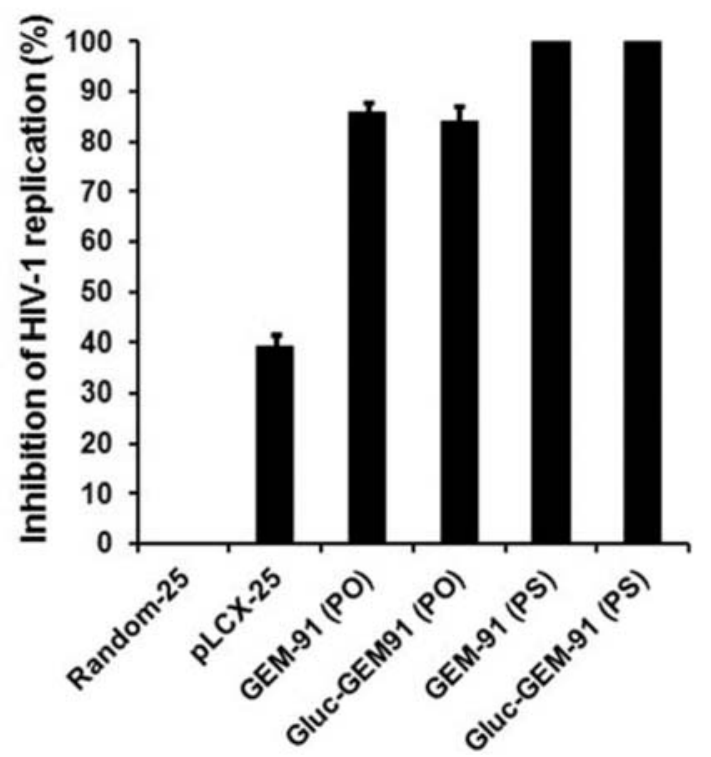

B)

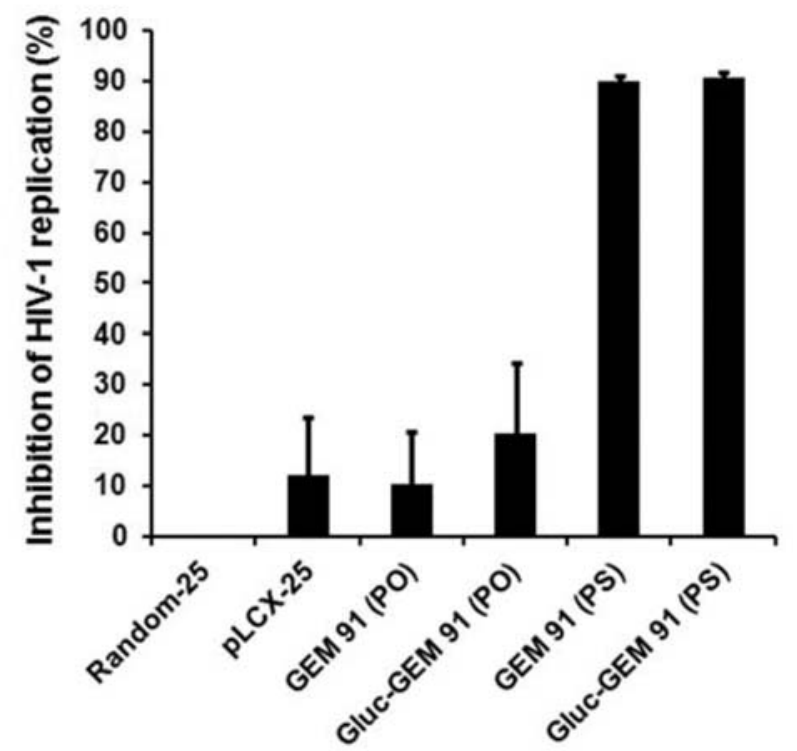


Figure 6
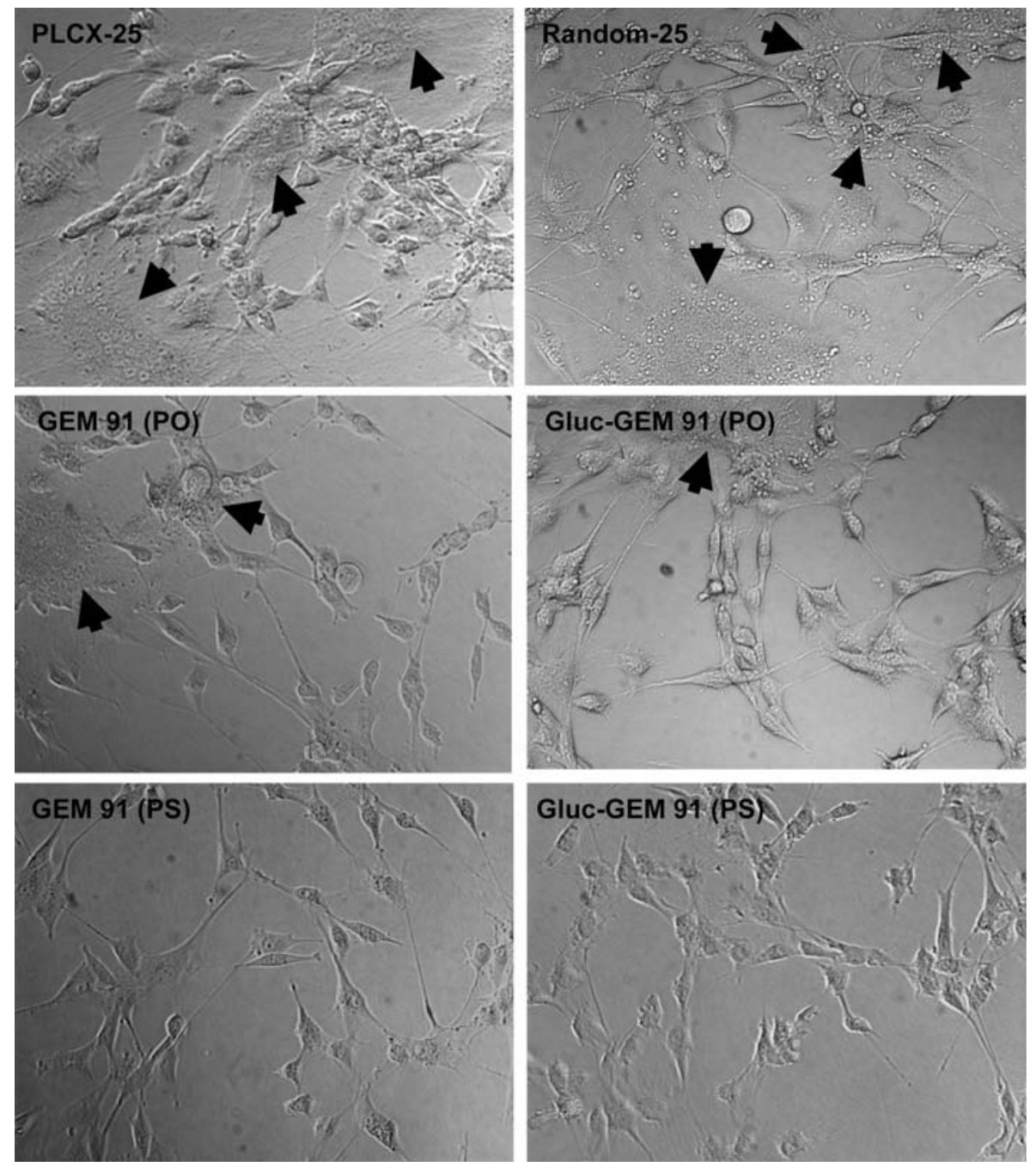
Figure 7

$\square 2$ days $\square 4$ days $\square 6$ days $\square 10$ days $\square 15$ days $\mathbf{2 0}$ days $\mathbf{m} 30$ days

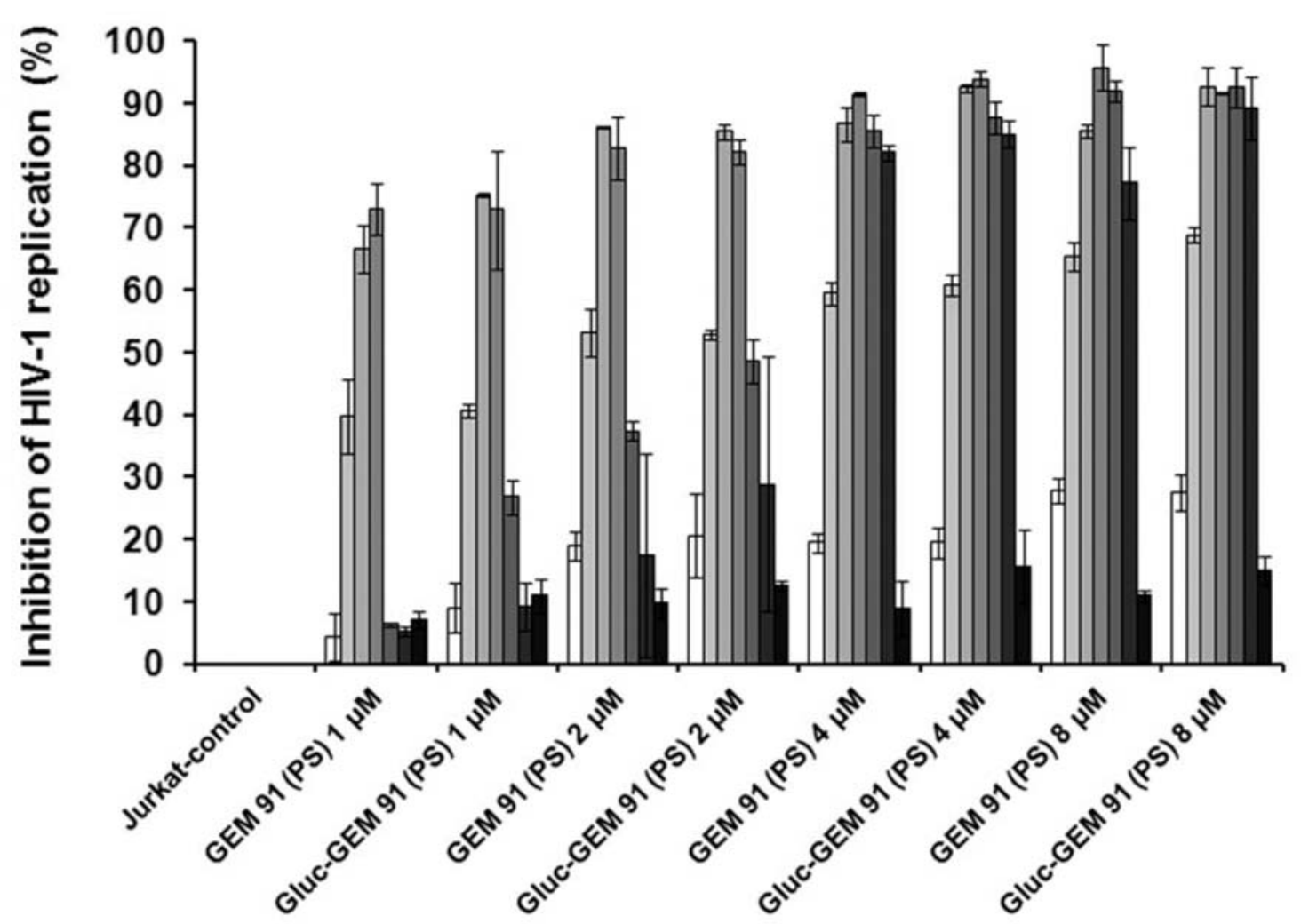


Figure 8

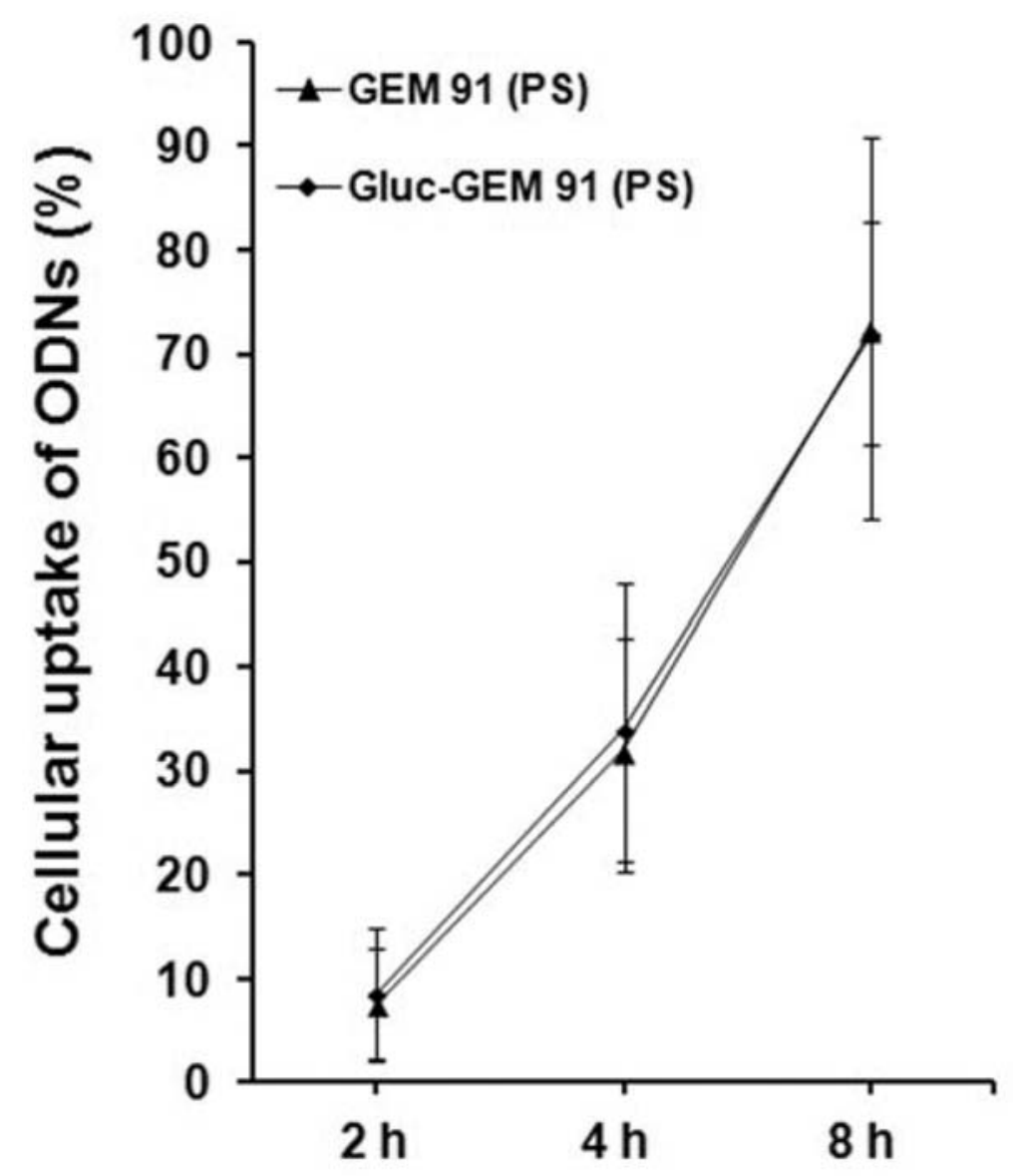


Figure 9

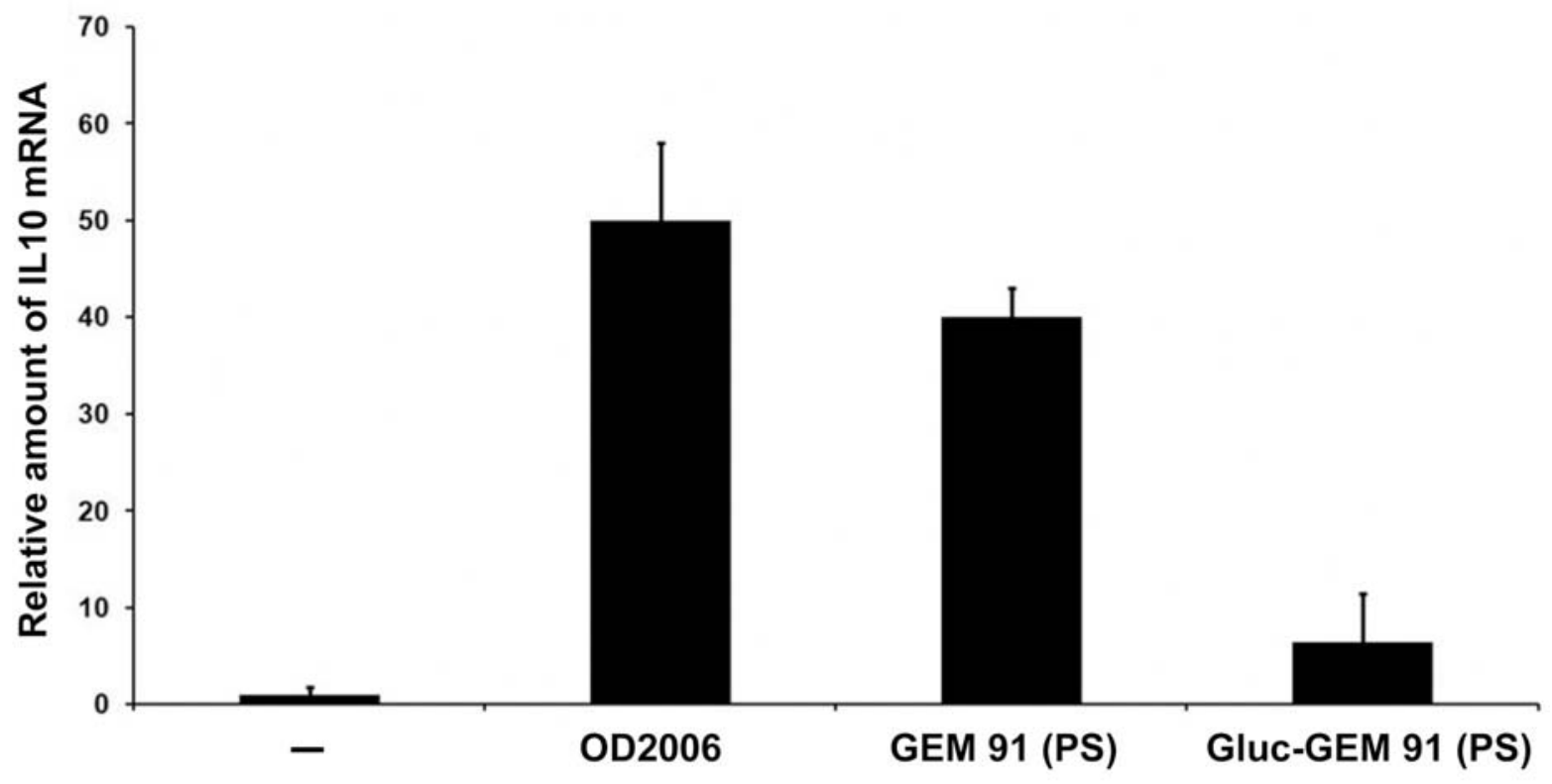

